\title{
Review
}

Pathobiology

\section{ICUS, IDUS, CHIP and CCUS: Diagnostic Criteria, Separation from MDS and Clinical Implications}

\author{
Peter Valent ${ }^{a, b}$

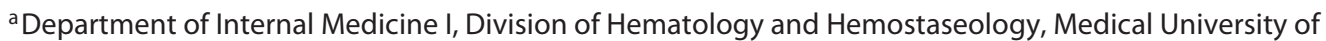 \\ Vienna, Vienna, Austria; ${ }^{b}$ Ludwig Boltzmann Cluster Oncology, Medical University of Vienna, Vienna, Austria
}

\begin{abstract}
Keywords
Myeloid neoplasms · Diagnostic criteria · Idiopathic cytopenia of uncertain significance $\cdot$ Idiopathic dysplasia of unknown significance $\cdot$ Clonal hematopoiesis with indeterminate potential · Clonal cytopenia of unknown significance
\end{abstract}

\begin{abstract}
Various myeloid neoplasms, including the myelodysplastic syndromes (MDS), bear a certain risk of progression to secondary acute myeloid leukemia (sAML). The evolution from low-risk to high-risk MDS and finally to sAML suggests that leukemogenesis is a multistep process. However, even before an overt neoplasm, such as an MDS, develops, "prediagnostic" clonal conditions may be identified. With the advent of large-scale genomic screens, such conditions may be detected quite frequently and early in apparently healthy individuals. Recent data suggest that these conditions increase with age and are indeed associated with an increased risk of
\end{abstract}

the occurrence of MDS or another myeloid neoplasm. In other patients, unexplained cytopenia may be detected and may precede MDS. More recently, diagnostic criteria for potential pre-MDS conditions, including idiopathic cytopenia of uncertain significance and clonal hematopoiesis with indeterminate potential, have been proposed. The current article provides an overview of pre-MDS states and related criteria through which these conditions can be discriminated from each other and from MDS. In addition, the clinical implications and management of pre-MDS states are discussed.

(c) 2018 S. Karger AG, Basel

\section{Introduction}

Myelodysplastic syndrome (MDS) is a term used for a group of myeloid neoplasms characterized by peripheral cytopenia, bone marrow (BM) failure, morphologic dysplasia in one or more blood cell lineages, and a genetic instability that results in an increased risk of transforma-

\section{KARGER}

(c) 2018 S. Karger AG, Basel

E-Mail karger@karger.com

www.karger.com/pat
Peter Valent, MD

Division of Hematology and Hemostaseology

Department of Internal Medicine I, Medical University of Vienna

Währinger Gürtel 18-20, AT-1090 Vienna (Austria)

E-Mail peter.valent@meduniwien.ac.at 
tion into secondary acute myeloid leukemia (sAML) [14]. The French-American-British (FAB) cooperative working group around John Bennett was the first to establish a widely accepted classification of MDS $[5,6]$. This classification was essentially based on cytomorphologic features of neoplastic cells in the BM and peripheral blood (PB). The FAB proposal served as a diagnostic and prognostic standard for many years and formed the conceptual basis for "later" classifications. Between 2001 and 2017, the World Health Organization (WHO) prepared updated versions of the initial proposal to classify MDS and disease-related criteria [7-9].

However, the clinical course and survival vary substantially among patients in various FAB and WHO cohorts, which is best explained by the excessive molecular and functional heterogeneity of MDS. In fact, disease evolution and prognosis vary greatly among patients, depending on somatic mutations, karyotypes, other features of the affected clone, and patient-related factors like age or comorbidities [1-4, 10-14].

During the past few years, several studies have shown that many mutations identified in patients with MDS are also detected in a subset of apparently healthy, elderly individuals [15-20]. Some of these people also have or develop mild cytopenia or mild leukocytosis, but the diagnostic criteria for MDS are not fulfilled [20]. Others have persistent unexplained cytopenia without morphologic or cytogenetic evidence of MDS (or other underlying disorders), a condition that has been referred to as idiopathic cytopenia of unknown significance (ICUS) [21-26].

It is worth noting that all of these conditions represent potential prephases of an MDS but may also precede other hematopoietic (myeloid or lymphoid) neoplasms. It is also important to note that in many of these cases blood counts remain stable and no evolution into MDS or another hematopoietic or non-hematopoietic disease is found even when the affected individuals are followed over many years. Therefore, it is important to define and study these conditions in more detail and to delineate them from other similar conditions and from early (lowrisk) MDS.

Over the past few years, several different proposals for the definition and classification of pre-MDS conditions have been published $[20,22,23,27]$. The current article provides and overview of these proposals and of the criteria used to discriminate pre-MDS conditions from each other and from low-risk MDS. In addition, the clinical implications and management of these conditions are discussed.

Pre-MDS Conditions

\section{Minimal Diagnostic Criteria for MDS}

MDS are multi-mutated clonal myeloid neoplasms characterized by PB cytopenia, BM failure, and substantial dysplasia in one or more myeloid cell types [1-4]. The clinical course in MDS is often indolent and stable. In other cases, however, MDS progresses to sAML within a short time. The diagnostic hallmark of MDS is BM cell dysplasia. MDS subtypes are diagnosed using criteria provided by the WHO classification [7-9]. This is a straightforward approach and a simple task as long as substantial dysplasia and marked cytopenia are present. However, in many cases, only mild cytopenia and no (or only mild) dysplasia are found. In these cases, it may be difficult to establish or exclude an overt MDS. There are also patients who have an abnormal (MDS-related) karyotype but only mild or no cytopenia and no overt BM or PB dysplasia [22, 27]. Other patients have transfusiondependent macrocytic anemia but no MDS-related karyotype, no molecular aberrations, and no dysplasia. Many of these cases and constellations have to be regarded as pre-MDS conditions rather than overt MDS [22, 27]. Moreover, several of these patients develop other myeloid neoplasms (other than MDS) or even a non-hematologic disease.

In order to separate MDS from other myeloid neoplasms and from pre-MDS states, diagnostic features were defined by the WHO in 2001, 2008 and 2016 [7-9]. A similar proposal focusing on minimal diagnostic MDS criteria was presented by a working group in 2007 [22]. These diagnostic criteria were updated and extended to pre-MDS states in 2017 [27]. The following MDS criteria were proposed.

Prerequisite criteria include: (1) persistent cytopenia over 4 months and (2) exclusion of any another, underlying etiology as the primary cause of cytopenia or dysplasia [27]. Any degree of cytopenia (even a mild cytopenia) qualifies as a prerequisite criterion of MDS provided that it persists and cannot be explained by another etiology. Both prerequisite criteria must be fulfilled to established the diagnosis MDS [22, 27].

MDS-related criteria include: (1) dysplastic features in at least $10 \%$ of all cells in one or more major blood cell lines (erythroid, neutrophilic, and megakaryocytic) or an elevation of ring sideroblasts to $\geq 15 \%$ (or to $\geq 5 \%$ when an SF3B1 mutation is found), (2) a myeloblast excess of 5-19\% in BM aspirate smears (and no AML-related gene defects are found in these cases) or 2-19\% circulating myeloblasts, and (3) detection of an MDS-associated chromosome abnormality (like $5 \mathrm{q}-,-7$, or a complex 
karyotype) [27]. At least one of these major MDS-related criteria must be fulfilled (together with the 2 prerequisite criteria) to establish a diagnosis of MDS [22, 27].

When MDS-related criteria are not met but the patient exhibits typical clinical features (e.g., substantial macrocytic anemia) and no other etiology is detected, MDS can still be considered as a (provisional) diagnosis when certain MDS co-criteria are fulfilled [22,27]. These co-criteria include MDS-related histopathological and immunohistochemical features, typical flow cytometry abnormalities of BM or PB cells, and MDS-associated somatic mutations. With regard to mutations, the number of mutations and the allele burden are also of diagnostic relevance. In overt MDS, the variant allele frequency (VAF) is usually higher than that found in clonal pre-MDS conditions. Moreover, in MDS multiple mutations are frequently detected, whereas this is not the case in pre-MDS states (when considering a VAF of at least $2 \%$ as standard). A number of more or less specific histomorphologic features and immunophenotypic abnormalities also support the conclusion that the patient is suffering from overt MDS [28-30]. For example, megakaryocyte dysplasia, abnormal expression of CD34 in megakaryocytes, focal accumulations of blast cells, or abnormal mast cells (may indicate concomitant systemic mastocytosis) can only be detected by a thorough histopathological and immunohistochemical investigation of BM section material. Similarly it is of the utmost importance to establish flow cytometry patterns in BM cells in all patients with suspected MDS [31-33]. Sometimes, flow cytometry analyses and/or histopathological analyses will reveal another myeloid neoplasm (such as hypoplastic AML, primary myelofibrosis, or systemic mastocytosis) as an underlying disease.

When all diagnostic evaluations and the co-criteria show negative results and the patient is classified as preMDS (e.g., ICUS), the recommendation is to follow the clinical course of the patient and to repeat clinical and laboratory examinations at certain time intervals (like in low-risk MDS) [22, 27]. A second BM examination may also be required in the follow-up, for example when MDS co-criteria are detected or the degree of cytopenia is suggestive of evolution into MDS [22,27].

\section{Potential Pre-MDS Conditions}

During the past 10 years, a number of potential preMDS conditions have been described, including ICUS, idiopathic dysplasia of unknown significance (IDUS),
Table 1. Overview of pre-MDS states and major diagnostic features

\begin{tabular}{|c|c|}
\hline Pre-MDS & Major diagnostic features and criteria \\
\hline ICUS & $\begin{array}{l}\text { Peripheral cytopenia }(\mathrm{s})^{\mathrm{a}}, \text { MDS criteria not fulfilled, } \\
\text { no MDS-related mutation }{ }^{\mathrm{b}} \text { found, no or only mild } \\
(<10 \%) \text { dysplasia, blast cells }<5 \%{ }^{\mathrm{c}}\end{array}$ \\
\hline CCUS & $\begin{array}{l}\text { Peripheral cytopenia }(s)^{\mathrm{a}}, \text { MDS criteria not fulfilled, } \\
\text { one or more MDS-related mutations }{ }^{\mathrm{b}} \text { found, no or } \\
\text { only mild }(<10 \%) \text { dysplasia, blast cells }<5 \%^{\mathrm{c}}\end{array}$ \\
\hline IDUS & $\begin{array}{l}\text { No peripheral cytopenia }{ }^{\mathrm{a}} \text {, MDS criteria not fulfilled, } \\
\text { no MDS-related mutation }{ }^{\mathrm{b}} \text { found, dysplasia in } \geq 10 \% \\
\text { of neutrophilic, erythroid, and/or megakaryocytes } \\
\text { found, blast cells }<5 \%^{c}\end{array}$ \\
\hline CHIP & $\begin{array}{l}\text { No peripheral cytopenia }{ }^{\mathrm{a}} \text {, MDS criteria not fulfilled, } \\
\text { one or more MDS-related mutations }{ }^{\mathrm{b}} \text { found, no or } \\
\text { only mild }(<10 \%) \text { dysplasia, blast cells }<5 \%^{\mathrm{c}}\end{array}$ \\
\hline
\end{tabular}

MDS, myelodysplastic syndromes; ICUS, idiopathic cytopenia of undetermined significance; CCUS, clonal cytopenia of undetermined significance; IDUS, idiopathic dysplasia of undetermined significance; CHIP, clonal hematopoiesis of indeterminate potential. ${ }^{\text {a }}$ Cytopenia of any degree counts as a criterion, but the cytopenia must persist for at least 4 months. ${ }^{b}$ Mutations may be detected by conventional cytogenetics, FISH, or sequencing studies. In sequencing studies, the variant allele frequency should be at least $2 \%$ to count as diagnostic. ${ }^{\mathrm{c}}$ Blast cells are detected by morphologic examination of blood and/or bone marrow smears. Flow cytometry studies and/or immunohistochemical studies (\% of CD34+ and/or KIT+ cells) can support microscopic examinations. In addition, flow cytometry studies may support the conclusion that the patient is suffering from MDS or another myeloid neoplasm rather than from a pre-MDS state.

clonal hematopoiesis of indeterminate (clinical) potential (CHIP), and clonal cytopenia of unknown significance (CCUS) (Table 1) [20-27, 34]. These conditions can be divided into: (1) cytopenic states (ICUS and CCUS) and non-cytopenic states (IDUS and CHIP) and (2) states with an unknown or negative mutation status (ICUS and IDUS) and cases with known (documented and relevant) somatic mutations (CHIP and CCUS). All of these conditions can persist without clinical manifestation or progression, but they can also develop into an overt MDS. However, these conditions can also progress into another myeloid neoplasm or other hematologic (lymphoid or mast cell) disorders or they may even convert to a nonhematologic (e.g., autoimmune or other inflammatory) disease. Therefore, the proposed appendices "US" (undetermined or unknown significance) and "IP" (indeterminate potential) are important and justified. These terms were also created with the idea of avoiding overdiagnosis 
Table 2. Recognized variants of ICUS

\begin{tabular}{ll}
\hline Variant of ICUS & Diagnostic features \\
\hline ICUS-A & $\begin{array}{l}\text { ICUS criteria fulfilled (MDS excluded); } \\
\text { persistent anemia (for at least } 4 \text { months), } \\
\text { normal platelet counts, and normal ANC }\end{array}$ \\
\hline ICUS-N & $\begin{array}{l}\text { ICUS criteria fulfilled (MDS excluded); } \\
\text { persistent neutropenia (for at least 4 months), } \\
\text { normal hemoglobin, and normal platelet } \\
\text { counts }\end{array}$ \\
\hline ICUS-T & $\begin{array}{l}\text { ICUS criteria fulfilled (MDS excluded); } \\
\text { persistent thrombocytopenia (for at least } \\
4 \text { months), normal hemoglobin, and normal } \\
\text { ANC }\end{array}$ \\
\hline ICUS-PAN & $\begin{array}{l}\text { ICUS criteria fulfilled (MDS excluded); } \\
\text { persistent bi- or pan-cytopenia (for at least 4 } \\
\text { months) }\end{array}$ \\
\hline
\end{tabular}

ICUS, idiopathic cytopenia of undetermined significance; MDS, myelodysplastic syndrome; ICUS-A, ICUS with anemia (or idiopathic anemia with unknown significance); ANC, absolute neutrophil count; ICUS-N, ICUS with neutropenia (or idiopathic neutropenia of unknown significance); ICUS-T, ICUS with thrombocytopenia (or idiopathic thrombocytopenia of unknown significance); ICUS-PAN, ICUS with bi- or pan-cytopenia (or bi- or pan-cytopenia of unknown significance).

and misdiagnosis at an early (pre) stage of cancer development [35]. In fact, it is well known that marked dysplasia and cytopenia occur in a number of different conditions and diseases (not only in MDS and pre-MDS) [36, 37]. Therefore, it is important that MDS and pre-MDS conditions are based on distinct criteria and that defined (standardized) investigations, including BM studies, are being performed before arrival at the diagnosis of a preMDS condition $[22,27]$. The following pre-MDS conditions have been defined (Table 1).

\section{Idiopathic Cytopenia of Unknown Significance}

ICUS is characterized by persistent cytopenia of any degree in one or more major blood cell lineages (erythrocytes, neutrophils, or platelets) (Table 1) [27]. In ICUS patients, the minimal diagnostic criteria for MDS are not met and the cytopenic state cannot be explained by any other (hematologic or non-hematologic) etiology [22, 27]. ICUS can be further split into ICUS-A (anemia), ICUS-N (neutropenia), ICUS-T (thrombocytopenia), and ICUS-PAN (bi/pancytopenia) (Table 2) [27]. The prognostic impact of this split remains uncertain. However, patients with ICUS-PAN may have a higher risk of transformation into an overt hematopoietic neoplasm compared to those with ICUS-A or ICUS-N. In patients with ICUS-T, platelet counts are usually higher than in patients with immune-mediated thrombocytopenia, where platelets can drop rapidly to very low counts. In patients with MDS-related features (e.g., macrocytic, transfusion-dependent anemia with low reticulocyte counts), further studies and markers (flow cytometry, cytogenetics, molecular, and immunohistochemical studies) need to be applied in order to confirm or exclude the presence of MDS or another BM neoplasm. Depending on the clinical features and laboratory test results, specific molecular markers (e.g., JAK2 V617F in the case of $\mathrm{BM}$ fibrosis) need to be applied.

The clinical course of ICUS is variable and unpredictable. In a subset of patients, progression to MDS or even AML is observed after a variable time period [21, 24, 26]. In other ICUS patients, a lymphoproliferative or mast cell neoplasm may develop.

In some patients with ICUS, a small-sized clone carrying typical chromosome_abnormalities (otherwise found in MDS or AML) is initially detected by FISH [21, 26,38 . These ICUS patients may have a higher risk of transformation into an overt MDS or another BM neoplasm compared to ICUS patients with any detectable small-sized (FISH+) clone. As soon as the size of the FISH-positive clone increases, or one or more MDS-associated somatic aberrations (mutations) are detected in a patient with ICUS, the diagnosis changes to CCUS provided that diagnostic criteria for the diagnosis MDS are not met (Table 1). Therefore, it is important to repeat cytogenetic and molecular studies during follow-up in patients with ICUS, IDUS, and CCUS, especially when signs of disease manifestation are found. In addition, it is equally important to perform these studies in patients with overt low-risk MDS [39].

\section{Idiopathic Dysplasia of Unknown Significance}

A number of reactive conditions and chronic, nonclonal disorders, such as autoimmune processes, can be accompanied by mild to marked signs of dysplasia in BM cells $[35,36]$. In addition, chronic treatment with certain (mostly anticancer) drugs can result in substantial dysplasia. In other cases with dysplastic BM or PB cells, no underlying etiology is found. In fact, more and more patients are referred with signs of mild or marked BM cell 
dysplasia, macrocytosis, pseudo Pelger cells or hypogranulated neutrophils. When no accompanying cytopenia and no MDS criteria are found, these patients should be diagnosed as having IDUS (Table 1 ) [23, 25, 27, 34]. It is important to note that several clonal conditions (BM neoplasms and CHIP) and non-clonal conditions (e.g., vitamin $B_{12}$ deficiency, copper deficiency, drug-induced dysplasia, and intoxication) have to be excluded before the diagnosis IDUS can be established [25, 27]. Sometimes, the etiology of BM and/or PB dysplasia is only detected after a follow-up period and reinvestigation of all relevant parameters. Therefore, IDUS is usually established as a provisional diagnosis and it is often replaced by a final diagnosis (underlying disease or overt MDS detected) during follow-up. However, in a few cases, IDUS remains as a diagnosis even after long-term observation and reinvestigation of all $\mathrm{PB}$ and $\mathrm{BM}$ parameters. In patients in whom persistent cytopenia and additional MDS-related criteria are also found, the diagnosis will change to MDS [27], and in those in whom molecular aberrations (MDSassociated mutations) are detected but no cytopenia and no other MDS-related features are found the diagnosis changes to CHIP. In other words, CHIP supersedes IDUS in the hierarchy of non-cytopenic pre-MDS conditions. The definition of IDUS is provided in Table 1.

\section{Clonal Hematopoiesis of Indeterminate (Clinical) Potential}

The diagnosis of CHIP is based on: (1) the presence of at least one somatic mutation that is relevant clinically and is otherwise found in MDS (or other myeloid neoplasms), (2) the absence of persistent cytopenia, and (3) the exclusion of MDS and of all other hematopoietic neoplasms (and other diseases) as underlying conditions (Table 1) [20, 27]. In this regard, it is important that various hematopoietic neoplasms may present without cytopenia. Therefore, a thorough investigation of the BM is always required (to exclude such BM neoplasms) to establish the diagnosis of CHIP $[20,27]$. Another important aspect is that the VAF of the detected aberration must be at least $2 \%$ to count as a CHIP-defining mutation [20,27]. The full definition of CHIP is provided in Table 1. In patients with CHIP, mild dysplasia may also be detected. However, as soon as persistent ( $\geq 4$ months) cytopenia also develops in the affected individual, the diagnosis changes to MDS.

The concept of CHIP is in line with the multi-hit and multi-phase concept of cancer evolution [35, 40, 41]. In fact, relevant somatic mutations may be acquired early during carcinogenesis by premalignant neoplastic stem cells that have no immediate capacity to produce a malignancy or even an expanding clone. Later, these clones expand slowly and can thus be detected in apparently healthy individuals using sequencing techniques, FISH, or flow cytometry. The earliest detectable phase of a hematopoietic (myeloid) neoplasm may be CHIP [20, 27, 35]. Later, pre-leukemic neoplastic stem cells acquire additional (transforming) hits and produce an overt neoplasm such as an MDS [35, 41]. Finally, the premalignant (stem) cells convert to fully malignant (leukemic) cells that give rise to an overt leukemia (in the case of MDS: sAML) $[35,40]$.

This concept implies that detectable somatic CHIP mutations (otherwise found in MDS, AML, or other BM neoplasms) increase with age. Indeed, CHIP mutations are primarily found in elderly (otherwise) healthy individuals. Therefore, CHIP has also been termed age-related clonal hematopoiesis [15-19, 42-44].

During the past few years, CHIP has primarily been analyzed in the context of MDS and AML. However, CHIP is a general phenomenon applicable to most if not all hematopoietic neoplasms. In fact, CHIP may also precede other lymphohematopoietic neoplasms, including myeloproliferative neoplasms, lymphomas, myelomas, or mastocytosis (Table 3). In addition, the presence of CHIP may bear a higher risk for the development of a therapy-related myeloid neoplasm such as tAML [4244]. However, not all patients exhibiting CHIP will develop an overt hematopoietic malignancy. More recently, it has been described that CHIP mutations also predispose to the development of atherosclerosis and related cardiovascular events [17, 45-47] (Table 3).

\section{Clonal Cytopenia of Unknown Significance}

In patients with CCUS, cytopenia and clonal abnormalities can be detected, but no dysplasia is seen and no other features (criteria) sufficient to diagnose MDS or another clonal BM neoplasm are found (Table 1) [20,27]. This definition implies that a number of examinations have to be performed (including a thorough BM investigation) to exclude MDS and to diagnose CCUS. As soon as dysplastic features, other MDS-related criteria, or multiple co-criteria are found, the diagnosis of CCUS changes to MDS. In a few patients, the delineation between CCUS and MDS may be difficult. For example, CCUS patient may present with mild dysplasia (below 10\%) or 
rare (not MDS-related) molecular or flow cytometric abnormalities. In some of these patients, overt MDS may be diagnosed in the follow-up. In other patients, another clonal BM disorder (e.g., myeloproliferative neoplasms) may develop. Concerning the minimal VAF required to establish the diagnosis CCUS, the same definition counts as for CHIP $(\geq 2 \%)$. In the presence of multiple mutations, the risk of progression from CHIP to MDS or AML may be higher.

\section{Recommended Evaluations to Separate Pre-MDS Conditions from MDS}

A number of clinical and laboratory examinations need to be performed to establish the diagnosis of MDS or the diagnosis of a pre-MDS condition. Standard laboratory studies include cytomorphological examinations of PB and BM cells, histopathological and immunohistochemical investigations, flow cytometry studies, conventional cytogenetics and FISH, and molecular sequencing studies using an assay that provides sufficient sensitivity (to detect VAF of less than $2 \%$ ), precision, and specificity [22, 27-30]. Serum chemistry studies should include all of the parameters required to exclude or detect: (1) a myeloid neoplasm (e.g., tryptase) or a lymphoid neoplasm (e.g., $\beta_{2}$-microglobulin and immunofixation), (2) a reactive condition, (3) a deficiency syndrome, and (4) toxic reactions. A detailed description of all of the recommended parameters is beyond the scope of this article. With regard to standards of evaluation and diagnostic algorithms, we refer to the available literature [22, 27-30].

\section{Practical Implications and Management of Pre-MDS States}

During the past few years, the emerging concept of pre-MDS conditions has received attention and acceptance from the scientific community. In addition, the clinical implications of such conditions have become clear. First, large-scale sequencing studies are being increasingly used for early cancer detection and to examine germline predisposition to cancer and other (e.g., cardiovascular) disorders. These studies will be translated into daily clinical practice and will thereby lead to an excessive number of (mostly older) subjects with CHIP. Many of these individuals with CHIP will be referred to hematology centers, which will represent a logistic and medical challenge for several reasons (Table 3) [35]. First, the
Table 3. Clinical and practical (management) implications of CHIP

Increased risk of development of a myeloid neoplasm

- MDS

- Acute myeloid leukemia

- MPN, including CML

- MDS/MPN overlap disorders

- Chronic eosinophilic leukemia

Increased potential risk of development of other hematologic neoplasms

- Lymphoproliferative neoplasms

- Mast cell neoplasms

Increased potential risk of development of a cardiovascular event

- In otherwise healthy individuals

- In patients who have other cardiovascular risk factors

- In patients who develop a myeloid neoplasm ${ }^{\mathrm{a}}$

- In patients with a myeloid neoplasm after eradication of the dominant clone ${ }^{\mathrm{b}}$

- In patients who will undergo SCT ${ }^{\mathrm{C}}$

- In patients who receive drugs that may trigger cardiovascular events $^{\mathrm{d}}$

Practical consequences and management issues

- Detailed investigation of hematopoietic organs including bone marrow

- Delineation from germ line mutations and common gene variants (SNP)

- Follow-up examinations (like in low-risk MDS)

- Recognition of the evolution to CCUS

- Early detection of cardiovascular risk profiles, especially in patients who develop a myeloid neoplasm

- Communication issues (how to explain it to the patient)

- Need to explore risk profiles in prospective studies

- Prophylactic strategies/recommendations (avoidance of additional risk factors)

- Computer-based models (to be used by physicians and patients)

CHIP, clonal hematopoiesis with indeterminate potential; SNP, single nucleotide polymorphism; CCUS, clonal hematopoiesis of uncertain significance; MDS, myelodysplastic syndrome; MPN, myeloproliferative neoplasm; CML, chronic myeloid leukemia; SCT, stem cell transplantation; SNP, single-nucleotide poly-

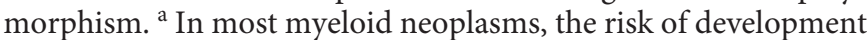
of a cardiovascular event is higher compared to age-matched healthy controls. Typical examples are JAK2-mutated myeloproliferative neoplasms and PDGFR-mutated eosinophilic leukemias. b Early molecular subclones exhibiting CHIP mutations but no driver lesions may survive therapy and may thus contribute (still) to the risk of development of a relapse or a cardiovascular event. ${ }^{c}$ Certain cardiovascular events, like veno-occlusive disease, may occur during or after SCT. ${ }^{\mathrm{d}}$ Certain drugs applied in hematology are associated with a higher risk of development of cardiovascular events (e.g., nilotinib, ponatinib, and thalidomide). 
prognostic implication of each (isolated) CHIP mutation and of the mutation patterns that may occur remains uncertain [35]. In order to exclude an overt or imminent BM neoplasm (like MDS) all of these individuals need to be examined in detail and many will undergo a BM examination and have to be controlled in the follow-up. The proposed definitions and criteria for pre-MDS conditions are helpful as a guide and may assist in preventing overdiagnosis and misdiagnosis, which is of special importance in healthy elderly individuals. In these cases, there may be no need for extensive reinvestigations in the follow-up unless overt signs of a full-blown MDS are detected. However, in younger adults with CHIP or CCUS it may be important to repeat all investigations within a relatively short time interval in order to exclude or document evolution to MDS or AML. Overall, the recommendation is to follow pre-MDS conditions in the same way as in patients with low-risk MDS (Table 3).

There are a number of additional issues and questions around pre-MDS conditions that have to be addressed in the near future. One question is whether a very low VAF (below 2\%) should also count as an indicator of CHIP or CCUS in future proposals $[27,35]$. Another question is whether management recommendations should also include avoidance of potential mutagenic events, such as smoking or radiation, in order to prevent the acquisition of additional somatic mutations that could lead to an overt MDS or AML in these cases. Similarly, the notion that CHIP is also associated with an increased risk of cardiovascular disorders and events is a critical point [17]. Although no clinical data are available yet, it seems logical to address this issue by informing the patients of the risk and by recommending avoidance and optimal treatment (management) of all other potential conditions and risk factors for cardiovascular diseases (smoking, hypertension, diabetes mellitus, and hyperlipidemia) (Table 3). In this regard it is also worth noting that patients with myeloid (myeloproliferative) neoplasm have an increased risk of developing cardiovascular events. A final important question is how the health care systems in various countries will address CHIP-related issues and implications. The central question may be whether the health care systems will be able to pay for the investigations, referrals, follow-up evaluation, and management of preMDS conditions.

\section{Acknowledgement}

We would like to thank Julia Neusiedler-Nicolas and Emir Hadzijusofovic for their excellent technical assistance.

\section{Disclosure Statement}

The author declares that he has no conflict of interest related to this study.

\section{Funding Sources}

This study was supported by the Austrian Science Fund (FWF; grants F4701-B20 and F4704-B20).

\section{Author Contributions}

The author established the concept of this review article, wrote the paper, and approved the final version of this work.

\section{References}

1 Nimer SD: Myelodysplastic syndromes. Blood 2008;111:4841-4851.

2 Bejar R, Levine R, Ebert BL: Unraveling the molecular pathophysiology of myelodysplastic syndromes. J Clin Oncol 2011;29:504-515.

3 Giagounidis A, Haase D: Morphology, cytogenetics and classification of MDS. Best Pract Res Clin Haematol 2013;26:337-353.

4 Malcovati L, Cazzola M: Refractory anemia with ring sideroblasts. Best Pract Res Clin Haematol 2013;26:377-385.

-5 Bennett JM, Catovsky D, Daniel MT, Flandrin G, Galton DA, Gralnick HR, Sultan C: Proposals for the classification of the myelodysplastic syndromes. Br J Haematol 1982;51: 189-199.

\footnotetext{
6 Bennett JM, Catovsky D, Daniel MT, Flandrin G, Galton DA, Gralnick HR, Sultan C, Cox C: The chronic myeloid leukaemias: guidelines for distinguishing chronic granulocytic, atypical chronic myeloid, and chronic myelomonocytic leukaemia - proposals by the FrenchAmerican-British Cooperative Leukaemia Group. Br J Haematol 1994;87:746-754.

7 Brunning RD, Bennett JM, Flandrin G, Matutes E, Head D, Vardiman JW, Harris NL: Myelodysplastic syndromes; in Jaffe ES, Harris NL, Stein H, Vardiman JW (eds): World Health Organization Classification of $\mathrm{Tu}$ mours: Pathology and Genetics of Tumours of Haematopoietic and Lymphoid Tissues. Lyon, IARC Press, 2001, vol 1, pp 62-73.
}

\footnotetext{
8 Vardiman JW, Thiele J, Arber DA, Brunning RD, Borowitz MJ, Porwit A, Harris NL, Le Beau MM, Hellström-Lindberg E, Tefferi A, Bloomfield CD: The 2008 revision of the World Health Organization (WHO) classification of myeloid neoplasms and acute leukemia: rationale and important changes. Blood 2009;114:937-951.

9 Arber DA, Orazi A, Hasserjian R, Thiele J, Borowitz MJ, Le Beau MM, Bloomfield CD, Cazzola M, Vardiman JW: The 2016 revision to the World Health Organization classification of myeloid neoplasms and acute leukemia. Blood 2016;127:2391-2405.
} 
10 Stauder R, Nösslinger T, Pfeilstöcker M, Sperr WR, Wimazal F, Krieger O, Valent P: Impact of age and comorbidity in myelodysplastic syndromes. J Natl Compr Canc Netw 2008;6: 927-934.

11 Malcovati L, Papaemmanuil E, Bowen DT, Boultwood J, Della Porta MG, Pascutto C, Travaglino E, Groves MJ, Godfrey AL, Ambaglio I, Gallì A, Da Vià MC, Conte S, Tauro S, Keenan N, Hyslop A, Hinton J, Mudie LJ, Wainscoat JS, Futreal PA, Stratton MR, Campbell PJ, Hellström-Lindberg E, Cazzola M: Clinical significance of SF3B1 mutations in myelodysplastic syndromes and myelodysplastic/myeloproliferative neoplasms. Blood 2011;118:6239-6246.

12 Schanz J, Steidl C, Fonatsch C, Pfeilstöcker M, Nösslinger T, Tuechler $\mathrm{H}$, Valent $\mathrm{P}$, Hildebrandt B, Giagounidis A, Aul C, Lübbert M, Stauder R, Krieger O, Garcia-Manero G, Kantarjian $\mathrm{H}$, Germing U, Haase D, Estey E: Coalesced multicentric analysis of 2,351 patients with myelodysplastic syndromes indicates an underestimation of poor-risk cytogenetics of myelodysplastic syndromes in the International Prognostic Scoring System. J Clin Oncol 2011;29:1963-1970.

13 Cargo C, Bowen D: Individual risk assessment in MDS in the era of genomic medicine. Semin Hematol 2017;54:133-140.

14 Steensma DP: The evolving role of genomic testing in assessing prognosis of patients with myelodysplastic syndromes. Best Pract Res Clin Haematol 2017;30:295-300.

15 Busque L, Patel JP, Figueroa ME, Vasanthakumar A, Provost S, Hamilou Z, Mollica L, Li J, Viale A, Heguy A, Hassimi M, Socci N, Bhatt PK, Gonen M, Mason CE, Melnick A, Godley LA, Brennan CW, Abdel-Wahab O, Levine RL: Recurrent somatic TET2 mutations in normal elderly individuals with clonal hematopoiesis. Nat Genet 2012;44:11791181.

16 Genovese G, Kähler AK, Handsaker RE, Lindberg J, Rose SA, Bakhoum SF, Chambert K, Mick E, Neale BM, Fromer M, Purcell SM, Svantesson O, Landén, Höglund M, Lehmann S, Gabriel SB, Moran JL, Lander ES, Sullivan PF, Sklar P, Grönberg H, Hultman CM, McCarroll SA: Clonal hematopoiesis and bloodcancer risk inferred from blood DNA sequence. N Engl J Med 2014;371:2477-2487.

17 Jaiswal S, Fontanillas P, Flannick J, Manning A, Grauman PV, Mar BG, Lindsley RC, Mermel CH, Burtt N, Chavez A, Higgins JM, Moltchanov V, Kuo FC, Kluk MJ, Henderson B, Kinnunen L, Koistinen HA, Ladenvall C, Getz G, Correa A, Banahan BF, Gabriel S, Kathiresan S, Stringham HM, McCarthy MI, Boehnke M, Tuomilehto J, Haiman C, Groop L, Atzmon G, Wilson JG, Neuberg D, Altshuler D, Ebert BL: Age-related clonal hematopoiesis associated with adverse outcomes. N Engl J Med 2014;371:2488-2498.
18 Xie M, Lu C, Wang J, McLellan MD, Johnson KJ, Wendl MC, McMichael JF, Schmidt HK, Yellapantula V, Miller CA, Ozenberger BA, Welch JS, Link DC, Walter MJ, Mardis ER, Dipersio JF, Chen F, Wilson RK, Ley TJ, Ding L: Age-related mutations associated with clonal hematopoietic expansion and malignancies. Nat Med 2014;20:1472-1478.

19 Young AL, Challen GA, Birmann BM, Druley TE: Clonal haematopoiesis harbouring AMLassociated mutations is ubiquitous in healthy adults. Nat Commun 2016;7:12484.

20 Steensma DP, Bejar R, Jaiswal S, Lindsley RC, Sekeres MA, Hasserjian RP, Ebert BL: Clonal hematopoiesis of indeterminate potential and its distinction from myelodysplastic syndromes. Blood 2015;126:9-16.

21 Wimazal F, Fonatsch C, Thalhammer R, Schwarzinger I, Müllauer L, Sperr WR, Bennett JM, Valent P: Idiopathic cytopenia of undetermined significance (ICUS) versus low risk MDS: the diagnostic interface. Leuk Res 2007;31:1461-1468.

22 Valent P, Horny HP, Bennett JM, Fonatsch C, Germing U, Greenberg P, Haferlach T, Haase D, Kolb HJ, Krieger O, Loken M, van de Loosdrecht A, Ogata K, Orfao A, Pfeilstöcker M, Rüter B, Sperr WR, Stauder R, Wells DA: Definitions and standards in the diagnosis and treatment of the myelodysplastic syndromes: consensus statements and report from a working conference. Leuk Res 2007;31:727-736.

23 Valent P, Horny HP: Minimal diagnostic criteria for myelodysplastic syndromes and separation from ICUS and IDUS: update and open questions. Eur J Clin Invest 2009;39:548-553.

24 Schroeder T, Ruf L, Bernhardt A, Hildebrandt B, Aivado M, Aul C, Gattermann N, Haas R, Germing U: Distinguishing myelodysplastic syndromes (MDS) from idiopathic cytopenia of undetermined significance (ICUS): HUMARA unravels clonality in a subgroup of patients. Ann Oncol 2010;21:2267-2271.

25 Valent P, Bain BJ, Bennett JM, Wimazal F, Sperr WR, Mufti G, Horny HP: Idiopathic cytopenia of undetermined significance (ICUS) and idiopathic dysplasia of uncertain significance (IDUS), and their distinction from low risk MDS. Leuk Res 2012;36:1-5.

26 Malcovati L, Cazzola M: The shadowlands of MDS: idiopathic cytopenias of undetermined significance (ICUS) and clonal hematopoiesis of indeterminate potential (CHIP). Hematology Am Soc Hematol Educ Program 2015; 2015:299-307.

27 Valent P, Orazi A, Steensma DP, Ebert BL, Haase D, Malcovati L, van de Loosdrecht AA, Haferlach T, Westers TM, Wells DA, Giagounidis A, Loken $M$, Orfao A, Lübbert $M$, Ganser A, Hofmann WK, Ogata K, Schanz J, Béné MC, Hoermann G, Sperr WR, Sotlar K, Bettelheim P, Stauder R, Pfeilstöcker M, Horny HP, Germing U, Greenberg P, Bennett JM: Proposed minimal diagnostic criteria for myelodysplastic syndromes (MDS) and potential pre-MDS conditions. Oncotarget 2017;8:73483-73500.
28 Horny HP, Sotlar K, Valent P: Diagnostic value of histology and immunohistochemistry in myelodysplastic syndromes. Leuk Res 2007; 31:1609-1616.

-29 Orazi A, Czader MB: Myelodysplastic syndromes. Am J Clin Pathol 2009;132:290-305.

30 Valent P, Orazi A, Büsche G, Schmitt-Gräff A, George TI, Sotlar K, Streubel B, BehamSchmid C, Cerny-Reiterer S, Krieger O, van de Loosdrecht A, Kern W, Ogata K, Wimazal F, Várkonyi J, Sperr WR, Werner M, Kreipe H, Horny HP: Standards and impact of hematopathology in myelodysplastic syndromes (MDS). Oncotarget 2010;1:483-496.

- 31 Malcovati L, Della Porta MG, Lunghi M, Pascutto C, Vanelli L, Travaglino E, Maffioli M, Bernasconi P, Lazzarino M, Invernizzi R, Cazzola M: Flow cytometry evaluation of erythroid and myeloid dysplasia in patients with myelodysplastic syndrome. Leukemia 2005; 19:776-783.

32 Westers TM, Ireland R, Kern W, Alhan C, Balleisen JS, Bettelheim P, Burbury K, Cullen M, Cutler JA, Della Porta MG, Dräger AM, Feuillard J, Font P, Germing U, Haase D, Johansson U, Kordasti S, Loken MR, Malcovati L, te Marvelde JG, Matarraz S, Milne T, Moshaver B, Mufti GJ, Ogata K, Orfao A, Porwit A, Psarra K, Richards SJ, Subirá D, Tindell $\mathrm{V}$, Vallespi T, Valent $\mathrm{P}$, van der Velden $\mathrm{VH}$, de Witte TM, Wells DA, Zettl F, Béné MC, van de Loosdrecht AA: Standardization of flow cytometry in myelodysplastic syndromes: a report from an international consortium and the European LeukemiaNet Working Group. Leukemia 2012;26:17301741.

33 Cremers EM, Westers TM, Alhan C, Cali C, Wondergem MJ, Poddighe PJ, Ossenkoppele GJ, van de Loosdrecht AA: Multiparameter flow cytometry is instrumental to distinguish myelodysplastic syndromes from non-neoplastic cytopenias. Eur J Cancer 2016;54:4956.

34 Valent P, Jäger E, Mitterbauer-Hohendanner G, Müllauer L, Schwarzinger I, Sperr WR, Thalhammer R, Wimazal F: Idiopathic bone marrow dysplasia of unknown significance (IDUS): definition, pathogenesis, follow up, and prognosis. Am J Cancer Res 2011;1:531541.

35 Valent P, Akin C, Arock M, Bock C, George TI, Galli SJ, Gotlib J, Haferlach T, Hoermann G, Hermine O, Jäger U, Kenner L, Kreipe H, Majeti R, Metcalfe DD, Orfao A, Reiter A, Sperr WR, Staber PB, Sotlar K, Schiffer C, Superti-Furga G, Horny HP: Proposed terminology and classification of pre-malignant neoplastic conditions: a consensus proposal. EBioMedicine 2017;26:17-24.

-36 Steensma DP: Dysplasia has a differential diagnosis: distinguishing genuine myelodysplastic syndromes (MDS) from mimics, imitators, copycats and impostors. Curr Hematol Malig Rep 2012;7:310-320. 
37 Valent P: Low blood counts: immune mediated, idiopathic, or myelodysplasia. Hematology Am Soc Hematol Educ Program 2012; 2012:485-491.

-38 Petrova-Drus K, Hasserjian R, Pozdnyakova O, Dal Cin P, Mathew S, Margolskee E, Orazi A, Geyer JT: Clinicopathologic evaluation of cytopenic patients with isolated trisomy 8: a detailed comparison between idiopathic cytopenia of unknown significance and low-grade myelodysplastic syndrome. Leuk Lymphoma 2016;7:1-9.

-39 Neukirchen J, Lauseker M, Hildebrandt B, Nolting AC, Kaivers J, Kobbe G, Gattermann N, Haas R, Germing U: Cytogenetic clonal evolution in myelodysplastic syndromes is associated with inferior prognosis. Cancer 2017; 123:4608-4616.

40 Hahn WC, Weinberg RA: Modelling the molecular circuitry of cancer. Nat Rev Cancer 2002;2:331-241.

41 Valent P, Bonnet D, De Maria R, Lapidot T, Copland M, Melo JV, Chomienne C, Ishikawa F, Schuringa JJ, Stassi G, Huntly B, Herrmann H, Soulier J, Roesch A, Schuurhuis GJ, Wöhrer S, Arock M, Zuber J, Cerny-Reiterer
S, Johnsen HE, Andreeff M, Eaves C: Cancer stem cell definitions and terminology: the devil is in the details. Nat Rev Cancer 2012;12: 767-775.

42 Gillis NK, Ball M, Zhang Q, Ma Z, Zhao Y, Yoder SJ, Balasis ME, Mesa TE, Sallman DA, Lancet JE, Komrokji RS, List AF, McLeod HL, Alsina M, Baz R, Shain KH, Rollison DE, Padron E: Clonal haemopoiesis and therapy-related myeloid malignancies in elderly patients: a proof-of-concept, case-control study. Lancet Oncol 2017;18:112-121.

43 Takahashi K, Wang F, Kantarjian H, Doss D, Khanna K, Thompson E, Zhao L, Patel K, Neelapu S, Gumbs C, Bueso-Ramos C, DiNardo CD, Colla S, Ravandi F, Zhang J, Huang X, Wu X, Samaniego F, Garcia-Manero G, Futreal PA: Preleukaemic clonal haemopoiesis and risk of therapy-related myeloid neoplasms: a case-control study. Lancet Oncol 2017;18:100-111.

44 Gibson CJ, Lindsley RC, Tchekmedyian V, Mar BG, Shi J, Jaiswal S, Bosworth A, Francisco L, He J, Bansal A, Morgan EA, Lacasce AS, Freedman AS, Fisher DC, Jacobsen E, Armand P, Alyea EP, Koreth J, Ho V, Soiffer RJ,
Antin JH, Ritz J, Nikiforow S, Forman SJ, Michor F, Neuberg D, Bhatia R, Bhatia S, Ebert BL: Clonal hematopoiesis associated with adverse outcomes after autologous stem-cell transplantation for lymphoma. J Clin Oncol 2017;35:1598-1605.

45 Jaiswal S, Natarajan P, Silver AJ, Gibson CJ, Bick AG, Shvartz E, McConkey M, Gupta N, Gabriel S, Ardissino D, Baber U, Mehran R, Fuster V, Danesh J, Frossard P, Saleheen D, Melander O, Sukhova GK, Neuberg D, Libby P, Kathiresan S, Ebert BL: Clonal hematopoiesis and risk of atherosclerotic cardiovascular disease. N Engl J Med 2017;377: 111-121.

46 Fuster JJ, MacLauchlan S, Zuriaga MA, Polackal MN, Ostriker AC, Chakraborty R, Wu CL, Sano S, Muralidharan S, Rius C, Vuong J, Jacob S, Muralidhar V, Robertson AA, Cooper MA, Andrés V, Hirschi KK, Martin KA, Walsh K: Clonal hematopoiesis associated with TET2 deficiency accelerates atherosclerosis development in mice. Science 2017;355: 842-847.

47 Shlush LI: Age related clonal hematopoiesis (ARCH). Blood 2018;131:496-504. 